\title{
Comparison of Intravenous Magnesium Sulphate and Lidocaine Effects on Attenuating Haemodynamic Variables to Laryngoscopy and Intubation in Patient Undergoing General Anesthesia
}

\section{Muhammad Azam, ${ }^{1}$ Muhammad Wasim Ali Amjad, ${ }^{2}$ Saadia Khaleeq, ${ }^{3}$ Naila Asad $^{4}$}

\begin{abstract}
Objective: To determine the effect of intravenous xylocaine and magnesium sulfate on attenuation of hemodynamic response to laryngoscopy and intubation in patients undergoing general anaesthesia.

Methods: This was a randomized controlled study carried out at operation theaters of services hospital lahore after obtaining approval from IRB of hospital. The data was collected over period of six month from 20.05.2020 to 20.12.2020 through electronic databases. 60 patients were divided into two groups of 30 each by lottery method in this randomized control trial. Intravenous magnesium sulphate $30 \mathrm{mg} / \mathrm{kg}$ diluted in 50 $\mathrm{ml}$ normal saline $15 \mathrm{~min}$ before induction was administered in $\mathrm{M}$ group and $50 \mathrm{ml}$ normal saline given in $\mathrm{L}$ group. Induction was done with propofol $2 \mathrm{mg} / \mathrm{kg}$, followed by suxamethonium $2 \mathrm{mg} / \mathrm{kg}$. I/V lignocaine 1.5 $\mathrm{mg} / \mathrm{kg}$ diluted in N/S (5ml) was given as bolus in L group and $5 \mathrm{ml} \mathrm{N} / \mathrm{S}$ IV bolus in M group 1 minute before intubation. Laryngoscopy was performed and the trachea was intubated after 1 minute. HR, systolic (SBP), diastolic (DBP) and mean arterial pressures (MAP) were measured just before securing intravenous access, just before induction, after intubation and 1,3,5 min post intubation.

Results: Mean age for both groups was $36.0 \pm 12.8$ and $38.2 \pm 10.8$. Mean HR was significantly different between two groups immediately after intubation $(p=0.010)$, and at 1,3 and 5 minutes also $(p=0.004, p=0.018$ and $p=0.024$ ) respectively. No significant difference was seen in systolic, diastolic and mean blood pressures at intubation, 1 minute, 3 minutes and 5 minutes after intubation among the groups ( $p>0.05)$.

Conclusion: Both Magnesian Sulfate and lignocaine are effective in attenuating haemodynamic response to laryngoscopy and intubation but magnesium sulphate provides better efficacy in control of heart rate.

Key Words: Haemodynamic response, laryngoscopy, Intubation, magnesium sulphate, lignocaine.

How to cite: Azam M., Amjad A.W.M., A. Khaleeq S., Asad N. Comparison of Intravenous Magnesium Sulphate and Lidocaine effects on attenuating haemodynamic variables to laryngoscopy and intubation in patient undergoing general anesthesia. Esculapio 2021; 17(01):65-70

DOI: https://doi.org/10.51273/esc21.2517113
\end{abstract}

\section{Introduction}

$\mathrm{L}$ aryngoscopy and endotracheal intubation induces a stress response that occurs due to sympathoadrenal stimulation. ${ }^{1,2,3,4}$ This pressor response leads to various cardiovascular changes such as increase in heart rate, rise in arterial blood pressure from baseline

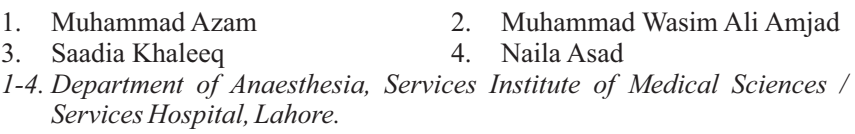

2. Muhammad Wasim Ali Amjad

4. Naila Asad

1-4. Department of Anaesthesia, Services Institute of Medical Sciences / Services Hospital, Lahore.

Correspondence:

Dr. Muhammad Azam, Department of Anaesthesia, Services Institute of Medical Sciences / Services Hospital, Lahore. Email: drazamanesthesia@yahoo.com and dysrhythmias. ${ }^{2}$ These transient cardiovascular responses may not affect normal healthy individuals but may increase perioperative morbidity and mortality in patients with coexisting disease such as ischemic heart disease, hypertension, cerebrovascular disease and diabetes mellitus. ${ }^{1,2}$

Several pharmacological and non-pharmacological methods were tried to minimize the adverse sympathoadrenal response at different times but few were found to be effective. Various drugs like lignocaine, magnesium sulphate, opioids, beta blockers, clonidine, labetalol, calcium channel blockers and vasodilators such as hydralazine have been used. ${ }^{1}$

The use of I/V magnesium sulfate $15 \mathrm{~min}$ before induction of anesthesia provide steady, smooth 
reduction and control of MAP and HR after intubation. This attenuation in hemodynamic response results from the inhibition of catecholamine release from the adrenal medulla and thus indirect vasodilation of blood vessels leading to a decrease in blood pressure. It also has a systemic and coronary vasodilation effect by antagonizing calcium ion in vascular smooth muscle. ${ }^{5}$

$2 \%$ lignocaine, an amide local anaesthetic, is most widely used to attenuate the stress response to laryngoscopy and intubation when given in dose of $1.5 \mathrm{mg} / \mathrm{kg}$ intravenously 90 seconds before induction. ${ }^{2}$ The beneficial effect of lidocaine is due to its direct cardiac depression and peripheral vasodilation, ability to suppress airway reflexes as well as antiarrhythmic properties. ${ }^{6}$ Lignocaine decreases airway reactivity by reducing release of substance $P$ and its glycinergic action. $^{7}$

Various studies have been done to compare intravenous magnesium sulphate with lignocaine and other drugs but efficacy is still controversial. The aims of the study to compare the effect of prophylactic use of IV magnesium sulfate with lidocaine on hemodynamics following laryngoscopy and intubation in patients undergoing general anaesthesia.

\section{Methods}

This was a randomized controlled study carried out at operation theaters of services hospital Lahore after obtaining approval from IRB of hospital. The data was collected over period of six months from 20.05. 2020 to 20.12.2020 through electronic databases. 60 patients scheduled for elective surgery were divided into two groups of 30 each by lottery method. Patients undergoing major head and neck surgeries under general anaesthesia with endotracheal intubation, aged 20-50 years of American Society of Anesthesiologists ASA I and II were included. Patients in whom difficult airway was anticipated, American Society of Anesthesiologists ASA III, patient with raised ICP, IHD, hypertensive and having diabetes mellitus were excluded.

IV access was established with $20 \mathrm{G}$ cannula. Baseline heart rate, BP, ECG and Oxygen saturation was recorded. Intravenous magnesium sulphate $30 \mathrm{mg} / \mathrm{kg}$ diluted in $50 \mathrm{ml}$ normal saline $15 \mathrm{~min}$ before induction was administered in M group and $50 \mathrm{ml}$ normal saline given in L group. All patients were premedicated with nalbuphine $0.1 \mathrm{mg} / \mathrm{kg}$ intravenously and induc- tion was done with propofol $2 \mathrm{mg} / \mathrm{kg}$, followed by suxamethonium $2 \mathrm{mg} / \mathrm{kg}$. I/V lignocaine $1.5 \mathrm{mg} / \mathrm{kg}$ diluted in N/S was given as bolus in L group and $5 \mathrm{ml}$ $\mathrm{N} / \mathrm{S}$ IV bolus in M group 1 min before intubation. A quick and gentle laryngoscopy not lasting for more than 15 second was then performed by one anesthetist and the trachea was intubated. Atracurium $0.25 \mathrm{mg} /$ $\mathrm{kg}$ intravenously was administered to maintain anaesthesia using oxygen with isoflurane $1 \%$ and IPPV.

Heart Rate (HR), systolic blood pressure (SBP), diastolic blood pressure (DBP) and mean arterial pressures (MAP) were measured just before securing intravenous access (baseline value), just before induction, after intubation and 1,3,5 min post intubation. Hypertension was considered when BP value was greater than $20 \%$ of baseline. Hypotension was considered when BP was less than $20 \%$ of baseline. Tachycardia was considered when HR was more than $20 \%$ of base line or HR greater than $100 \mathrm{bpm}$. Bradycardia was labelled when HR was lower than 50 bpm.

The data for age, weight, SBP, DBP, MAP, and HR were all described by using "Mean \pm SD". The comparison between two groups at baseline, immediately after intubation, one, three and five minutes after intubation were made by using independent sample ttest. Comparison of each hemodynamic parameter with its baseline value within each group was made by using paired t-test. P-value 0.05 was considered statistically significant. Line graphs were used to present the changes from baseline to 5 minutes after intubation for each parameter.

\section{Results}

The mean age for both groups was $36.0 \pm 12.8$ and $38.2 \pm 10.8$ which was insignificantly different between two groups, beside this the weight, systolic diastolic and mean arterial pressure were all insignificantly different at baseline with p-values $0.755,0.877,0.692$ and 0.824 respectively. The heart rate for $\mathrm{L}$ group at baseline was $93.0 \pm 19.3$ and that for $M$ group was $86.7 \pm 15.6$ and this difference was also insignificant with p-value 0.168. (Table.1)

As the baseline values were all insignificant so direct comparisons were made at each instance at and after intubation between two groups. The systolic, diastolic and mean blood pressures were not found significant at intubation, and 1, 3 and 5 minutes after intubation between two groups. The mean heart rate, however, 
immediately after intubation was found significantly different between two groups with p-value 0.010 , and at 1,3 and 5 minutes also were significantly different with p-values $0.004,0.018$ and 0.024 respectively. (table.2)

When compared within group the systolic blood pressure raised a bit from baseline in both groups till

Table 1: Demographic and Hemodynamic Parameters at Start of Study after Randomization

\begin{tabular}{|c|c|c|c|c|c|}
\hline & \multicolumn{4}{|c|}{ Group } & \multirow{3}{*}{$\begin{array}{c}\text { P-value } \\
\text { comparison } \\
\text { between } \\
\text { groups }\end{array}$} \\
\hline & \multicolumn{2}{|c|}{$\begin{array}{c}\mathbf{L} \\
(n=30)\end{array}$} & \multicolumn{2}{|c|}{$\begin{array}{c}M \\
(n=30)\end{array}$} & \\
\hline & Mean & SD & Mean & SD & \\
\hline Age & 36.0 & 12.8 & 38.2 & 10.8 & 0.474 \\
\hline Weight (kgs) & 66.6 & 10.2 & 67.5 & 12.7 & 0.755 \\
\hline SBP & 134.3 & 13.1 & 133.7 & 18.0 & 0.877 \\
\hline DBP & 82.7 & 12.4 & 83.9 & 11.6 & 0.692 \\
\hline MAP & 102.2 & 12.1 & 102.9 & 12.3 & 0.824 \\
\hline HR & 93.0 & 19.3 & 86.7 & 15.6 & 0.168 \\
\hline
\end{tabular}

immediate after intubation but this raise was insignificant. The p-value for immediately after intubation was 0.108 in group L and 0.057 in M. At one 1 minute after intubation the SBP declined and p-values for two groups were $<0.001$ and 0.005 respectively. The mean systolic blood pressure reached to $104 \mathrm{mmHg}$ for group $\mathrm{L}$ and $105 \mathrm{mmHg}$ for group $\mathrm{M}$ at 5 minutes and both were highly significant as compared to baseline with $p$-values $<0.001$. (Table.2, fig.1)

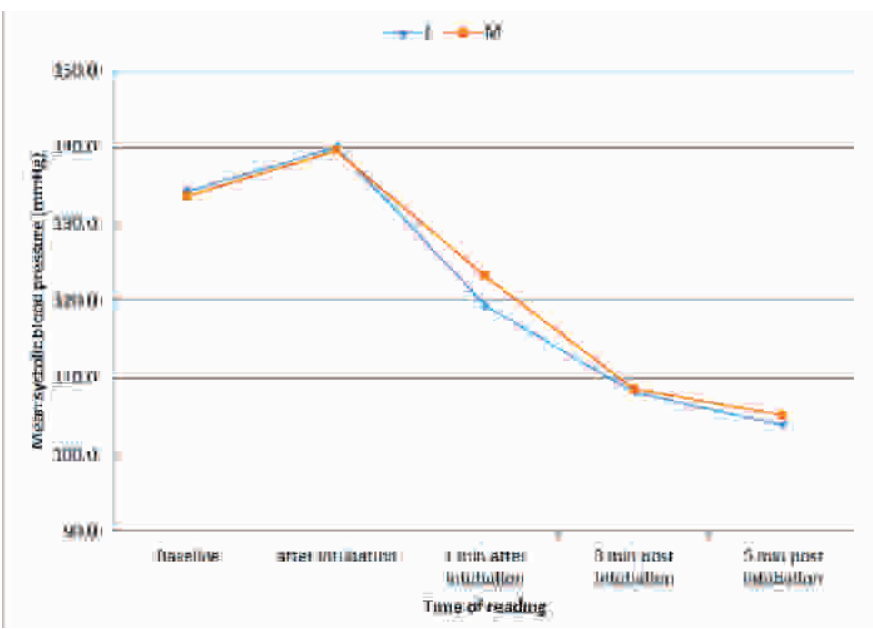

Figure.1: Systolic Blood Pressure for Patients in Two Groups from Baseline to 5 Minutes after Intubation The pattern for diastolic blood pressure was not diffe-

Table 2: : Comparison of Hemodynamic Parameters from Baseline within Group and between Groups at Each Reading Time After Intubation

\begin{tabular}{|c|c|c|c|c|c|}
\hline & \multicolumn{4}{|c|}{ Group } & \multirow[b]{3}{*}{$\begin{array}{c}\text { P-value } \\
\text { comparing } \\
\text { two groups }\end{array}$} \\
\hline & \multicolumn{2}{|c|}{$\mathbf{L}$} & \multicolumn{2}{|r|}{$\mathbf{M}$} & \\
\hline & Mean \pm SD & $\begin{array}{c}\text { P-value } \\
\text { Within group } \\
\text { comparison to } \\
\text { base line }\end{array}$ & Mean \pm SD & $\begin{array}{c}\text { P-value } \\
\text { Within group } \\
\text { comparison to base } \\
\text { line }\end{array}$ & \\
\hline \multicolumn{6}{|l|}{ SBP } \\
\hline immediately after intubation & $140.1 \pm 18.1$ & 0.108 & $139.6 \pm 23.1$ & 0.057 & 0.931 \\
\hline $1 \mathrm{~min}$ after intubation & $119.4 \pm 16.9$ & $<0.001$ & $123.2 \pm 15.4$ & 0.005 & 0.359 \\
\hline 3 min post intubation & $108.2 \pm 14.7$ & $<0.001$ & $108.5 \pm 13.1$ & $<0.001$ & 0.934 \\
\hline $5 \mathrm{~min}$ post intubation & $103.9 \pm 13.2$ & $<0.001$ & $105.1 \pm 14.6$ & $<0.001$ & 0.740 \\
\hline \multicolumn{6}{|l|}{ DBP } \\
\hline immediately after intubation & $94.6 \pm 14.9$ & 0.001 & $95.1 \pm 16.0$ & $<0.001$ & 0.914 \\
\hline $1 \mathrm{~min}$ after intubation & $77.4 \pm 12.6$ & 0.054 & $82.9 \pm 16.5$ & 0.762 & 0.152 \\
\hline 3 min post intubation & $68.0 \pm 13.0$ & $<0.001$ & $70.0 \pm 13.7$ & $<0.001$ & 0.556 \\
\hline $5 \mathrm{~min}$ post intubation & $64.0 \pm 10.9$ & $<0.001$ & $66.7 \pm 12.4$ & $<0.001$ & 0.381 \\
\hline \multicolumn{6}{|l|}{ MAP } \\
\hline after intubation & $109.7 \pm 16.8$ & 0.027 & $110.3 \pm 15.9$ & 0.008 & 0.881 \\
\hline 1 min post intubation & $92.4 \pm 13.1$ & 0.002 & $94.0 \pm 17.1$ & 0.008 & 0.692 \\
\hline 3 min post intubation & $82.1 \pm 13.4$ & $<0.001$ & $83.1 \pm 13.0$ & $<0.001$ & 0.763 \\
\hline 5 min post intubation & $77.6 \pm 11.7$ & $<0.001$ & $80.2 \pm 13.2$ & $<0.001$ & 0.410 \\
\hline \multicolumn{6}{|l|}{ HR } \\
\hline post-intubation & $104.2 \pm 13.2$ & 0.003 & $95.8 \pm 11.2$ & 0.003 & 0.010 \\
\hline 1 mins after intubation & $98.2 \pm 13.1$ & 0.099 & $88.6 \pm 11.4$ & 0.504 & 0.004 \\
\hline 3 mins after intubation & $90.7 \pm 14.9$ & 0.402 & $82.6 \pm 10.6$ & 0.107 & 0.018 \\
\hline 5 min after intubation & $86.0 \pm 12.4$ & 0.006 & $78.6 \pm 12.4$ & 0.001 & 0.024 \\
\hline
\end{tabular}


rent than systolic. It also raised immediately after intubation to 94.6 and $95.1 \mathrm{mmHg}$ in two groups and this raise was significant with p-value 0.001 in $\mathrm{L}$ and $<0.001$ in M group. The decline after one minute was insignificant in group L with p-value 0.054 and in group $\mathrm{M}$ with $\mathrm{p}$-value 0.762 . Later DBP continued to decline significantly in both groups with p-values $<0.001$. (Table.2, fig.2)

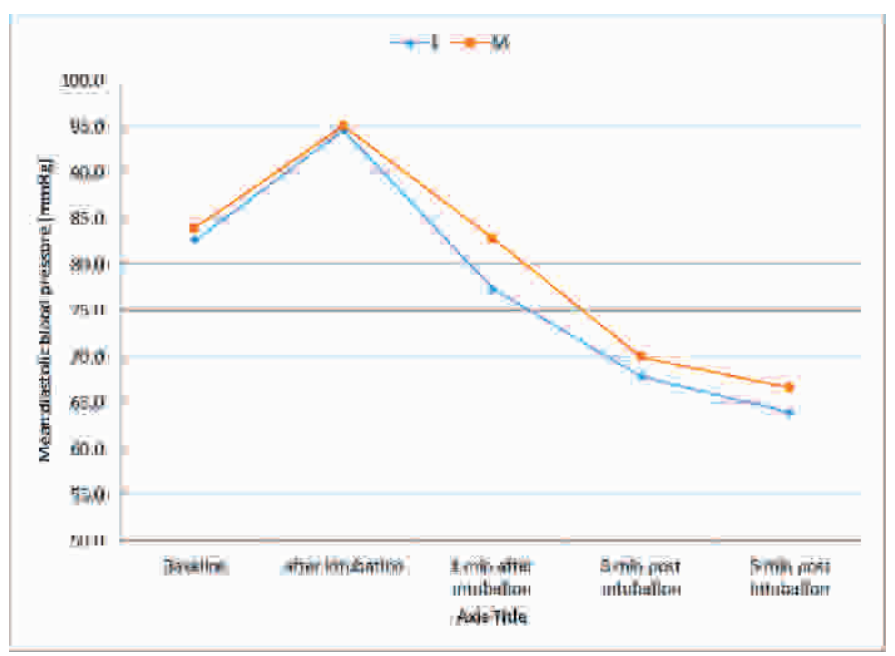

Figure.2: Diastolic Blood Pressure for Patients in Two Groups from Baseline to 5 Minutes After Intubation

The mean arterial pressure increased significantly in both groups immediately after intubation $(\mathrm{p}=0.002 \&$ $\mathrm{p}=0.008$ ) and then declined in both groups significantly at each reading time as compared to baseline. At five minutes the MAP was $77.6 \pm 11.7$ in group L and $80.2 \pm 13.2$ in group M. (Table.2, Fig.3)

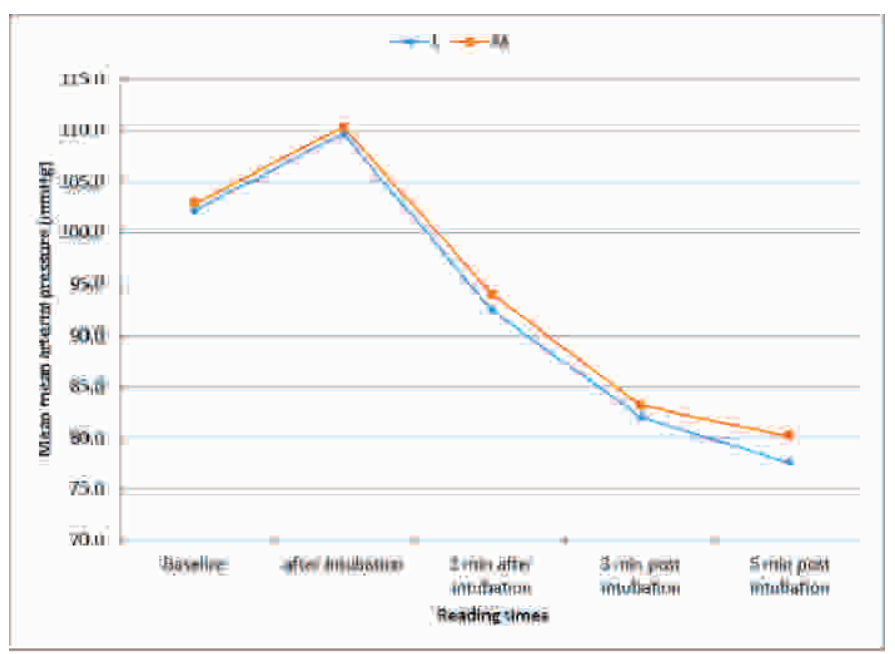

Figure.3: Mean Arterial Pressure for Patients in Two Groups from Baseline to 5 Minutes after Intubation

The heart rate in group L rose to $104.2 \pm 13.2$ immediately after intubation and this raise was highly significant with p-value 0.003 . In group $M$ the heart rate increased to $95.8 \pm 11.2$ and this increase was also significant with p-value 0.003 . It declined after one minute in both groups but the decline was insignificant in both groups with p-values 0.099 and 0.504 respectively. Even after 3 minutes of intubation the heart rate was insignificantly different in both groups with p-values 0.402 and 0.107 . Later, after 5 minutes, the heart rate declined in group L to $86.0 \pm 12.4$ with pvalue 0.006 and in group $M$ to $78.6 \pm 12.4$ with a $p$ value 0.001 . (Table.2, Fig.4)

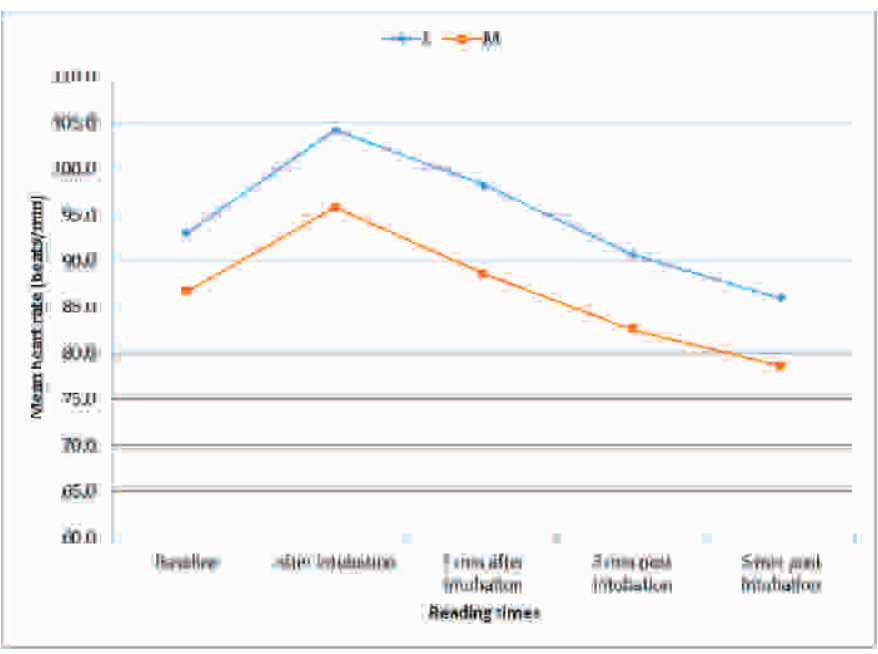

Figure.4: Heart rate for Patients in Two Groups from Baseline to 5 Minutes after Intubation

\section{Discussion}

Laryngoscopy and intubation, being noxious stimuli, incite remarkable sympathetic activity. Studies have shown an increase in heart rate with intubation and a greater increase in blood pressure with direct laryngoscopy. ${ }^{6}$ This pressor response, arises 30 s after laryngoscopy and intubation and returns to baseline values steadily within 5-10 min. These transitory responses usually produce no consequences in healthy individuals but may be harmful to the patients having reactive airways, hypertension, coronary artery disease, myocardial insufficiency and cerebrovascular diseases. ${ }^{1}$

Common factors precipitating the pressor response to laryngoscopy and intubation are light planes of anaesthesia, prolonged time for the procedure, elevation of vagally innervated posterior part of epiglottis by straight/ Miller blade, anatomically difficult view, greater force used to displace the tongue and more manipulations/ attempts at laryngoscopy and intubation. Several drugs and maneuvers have been used for mitigating this stress response with variable benefits and side effects. 
Magnesium Sulphate and lignocaine 2\% appear to meet the characteristic of a drug to prevent these sympathetic response. Comparison of magnesium sulphate with lignocaine in our study did not show significant difference in systolic, diastolic and mean blood pressures at intubation, 1 minute, 3 minutes and 5 minutes after intubation among the groups $(\mathrm{p}>$ $0.05)$. However, the mean heart rate decreased significantly in Magnesium group after 1, 3 and 5 minutes of intubation when compared to Lignocaine $(p=0.01$, $\mathrm{p}=0.00$, and $\mathrm{p}=0.02$ ).

In 2017, Bhalerao NS showed similar result to our study as there was no significant increase in BP after laryngoscopy when compared with base line with use of intravenous $\mathrm{MgSO} 450 \mathrm{mg} / \mathrm{kg}$ and lignocaine $2 \mathrm{mg} / \mathrm{kg}$ in hypertensive patients.

In accordance to our study, Rajan Sunil observed there was a statistically significant decrease in HR from the pre-induction values in $\mathrm{MgSO} 4$ group $(50 \mathrm{mg} / \mathrm{kg})$ than lignocaine group up to $15 \mathrm{~min}$ following intubation. Although there was decrease in systolic blood pressure, diastolic blood and mean arterial pressure from induction values in both groups, there was no significant difference between the groups.'

Kiaee $\mathrm{M}$ et al concluded similar results regarding heart rate changes when comparing magnesium sulphate with lignocaine. Difference in results were shown in systolic, diastolic and mean arterial pressures. In contradiction to our study results they found greater decrease in systolic, diastolic and mean arterial pressures with lignocaine. $^{5}$

Padmawar S in 2016 found comparable results to our study. The difference in attenuation of heart rate was significant among groups but no significant difference was seen in SBP, DBP and MAP in comparison of lignocaine and magnesium sulphate groups at intubation, 1 minute, 3 minute and 5 minutes after intubation. Magnesium sulphate group was found better than lignocaine. $^{2}$

Consistent with our results, significant fall in heart rate was noted by Vallabha et al following induction, laryngoscopy, and intubation when comparing magnesium $(30 \mathrm{mg} / \mathrm{kg})$ with lignocaine $(1.5 \mathrm{mg} / \mathrm{kg})$ group. The decrease in mean arterial pressure was significant unlike the results of our study. ${ }^{3}$

Nooraei $\mathrm{N}$ et al used $60 \mathrm{mg} / \mathrm{kg}$ magnesium sulphate and lignocaine $1.5 \mathrm{mg} / \mathrm{kg}$ in 60 patient and concluded there was significant decrease in heart rate with lignocaine at $3 \mathrm{rd}$ and 4 th minutes after intubation that were contrary to our results. But similarity was seen in the results of systolic, diastolic and mean arterial pressures with no significant difference among both groups. ${ }^{10}$

In 2017 CCRGA evaluated 56 patient and found different result from our study. There was increase in heart rate and blood pressure after laryngoscopy and intubation compared to baseline. The reason may be they used bispectral index in their study to assess the depth of anesthesia which is not used in our study.

In 2011 SH Majid Waseem et all found different result from our study. They found lignocaine was more effective and efficacious than magnesium sulphate. In 89 patients they used intravenous $1 \%$ lignocaine $1 \mathrm{mg} / \mathrm{kg}$ and magnesium sulphate $10 \mathrm{mg} / \mathrm{kg}$ instead of $1.5 \mathrm{mg} / \mathrm{kg}$ lignocaine and $30 \mathrm{mg} / \mathrm{kg}$ magnesium sulphate intravenous in our study. ${ }^{11}$

We did not monitor depth of anaesthesia due to unavailability of Bispectral Index and also used suxamethonium for intubation instead of nondepolarizing muscle relaxant. In future, research can be planned to evaluate these limitations of our study.

\section{Conclusion}

Both Magnesian Sulfate $(30 \mathrm{mg} / \mathrm{kg})$ and IV lignocaine $(1.5 \mathrm{mg} / \mathrm{kg})$ are effective in attenuating haemodynamic response to laryngoscopy and intubation without any deleterious effects. However, magnesium sulphate provides better efficacy in control of heart rate.

\section{Conflict of Interest: None}

\section{References}

1. A comparative study of two doses of magnesium sulphate in attenuating haemodynamic responses to laryngoscopy and intubation. Kotwani MB, Kotwani DM, Laheri V. Int J Res Med Sci. 2016 Jul;4(7):25482555

2. Padmawar, Manish Patil, A Comparative study of $2 \%$ Lignocaine vs 50\% Magnesium Sulphate for Attenuation of Stress Responses to Laryngoscopy and Endotracheal Intubation, 2016;3:8.

3. Vallabha R, Muthayala VK. Attenuating the Haemodynamic Stress To Laryngoscopy And Intubation With I.V. Magnesium Sulphate And LignocaineComparative Study. OSR-JDMS 2018;17(4):19-27.

4. Mahajan L, Manjkot, Attenulation of the pressor 
responses to laryngoscopy and endotracheal intubation with intravenous dexmdetomidine versus magnesium sulphate under bispectral index-controlled anaesthesia: a placebo-controlled prospective randomized trial, 2018;62:5:337-343.

5. Mesbah Kiaee M, Safari S, Movaseghi G R, Mohaghegh Dolatabadi M R, Ghorbanlo M, et al. The Effect of Intravenous Magnesium Sulfate and Lidocaine in Hemodynamic Responses to Endotracheal Intubation in Elective Coronary Artery Bypass Grafting: A Randomized Controlled Clinical Trial, Anesth Pain Med. 2014 ; 4(3):e15905

6. Jain P, Vats A. Comparison of Esmolol and Lidocaine for Blunting of Stress Response during Laryngoscopy and Endotracheal Intubation. Int J Sci Stud 2017;5(8):12-17.

7. Mendonca FT. Effects of Lidocaine and Magnesium sulfate in attenuating hemodynamic response to tracheal intubation: single-center, prospective, double-blind, randomized study, Rev Bras Anestestiol. 2017; 67(1):
50-56.

8. Bhalerao NS, Modak A, Belekar V. Comparison between magnesium sulfate $(50 \mathrm{mg} / \mathrm{kg})$ and lignocaine $(2 \mathrm{mg} / \mathrm{kg})$ for attenuation of intubation response in hypertensive patients. J Datta Meghe Inst Med Sci Univ 2017;12:118-20.

9. Rajan S, Kavita M, Andrews S. The attenuating effect of magnesium on hemodynamic responses during transphenodial surgery. Amrita J Med 2012;8:31-2.

10. Nooraei N, Dehkodi ME, Radpay B. et al. effects of intravenous magnesium sulfate and lidocaine on hemodynamic variable following direct laryngoscopy and intubation in elective surgery patients. Tanaffos. 2013:12:57-63.

11. Waseem SHM, Khurshid T. Comparison of the efficacy of single bolus intravenous lignocaine with magnesium sulphate to attenuate the haemodynamic response of laryngoscopy and intubation. 2011;4:4. 